\title{
IoT innovation clusters in Europe and the case for public policy
}

\author{
Luca Alessandro Remotti* \\ IT and Digital Transformation Department, Data Power Srl, Cagliari, Italy \\ *Corresponding author. E-mail: luca.remotti@data-power.net \\ Evidence-based Strategic Advice and Policy Research.
}

Received: 28 January 2021; Revised: 14 June 2021; Accepted: 15 June 2021

Key words: economic and industrial impacts; innovation cluster policy; IoT clusters; IoT enablers; IoT regulations

\begin{abstract}
Abbreviations: AI, artificial intelligence; B2B, business to business; CAGR, compound annual growth rate; EU, European Union; ICT, information and communication technologies; IoT, Internet of Things; IPv6, Internet Protocol v6; Learning DUI, learning by doing, using and interacting; LMCs, large multinational companies; ML, machine learning; OECD, Organization for Economic Cooperation and Development; R\&D, research and development; RTOs, research and technology organizations; SMEs, small and medium-sized enterprises; VC, venture capital.
\end{abstract}

\begin{abstract}
The Internet of Things (IoT) is currently developing fast and its potential as driver of innovative solutions is increasing, pushed by technologies, networks, communication, and computing power, and has the potential to drive the development of technological ecosystems, such as innovation clusters. Innovation clusters are agglomeration of enterprises and research organizations, which cooperate, interact and compete, generating innovation and driving the growth of ecosystems. The narrative around innovation clusters has been developing since many years and policy-makers seek to use such clusters as a policy instrument to support the growth of technology on the one hand and regional and sectoral development on the other hand. This policy paper expands an empirical study on IoT innovation clusters in Europe and places it within the current debate around clusters and innovation clusters to provide evidence-based advice to policy-makers on what may and may not work as public policy measures. The paper highlights the findings of the interaction with several hundred European IoT innovation clusters and points out their points of view on their own creation factors, operational characteristics, and success stories, as well as their expectations in respect to policy interventions for IoT and for clusters. Suggestions for IoT policy-making are provided. The paper has also undertaken an extensive review of up-to date research on innovation cluster creation and performance, thoroughly analyzing the real possibility to define causal relationships between clusters, productivity and economic growth, and business performance, and providing suggestions for policy-makers on the approach to cluster policy.
\end{abstract}

\section{Policy Significance Statement}

This research is significant for policy-makers since it provides a detailed insight on the ecosystem of IoT innovation clusters in Europe, on their factors of establishment, development, and success. It provides input to policy measures both for cluster support and for IoT development, basing it on extensive data collection through surveys and case study interviews. The study research was designed to capture and structure the input of cluster members and IoT players, who have clearly stated their priorities in respect to policy measures and soft policy 
actions. These inputs have been matched with relevant research papers analyzing the impacts of public policies on cluster formation and development and the achievable wider economic, industrial, employment, and societal impacts.

\section{Introduction}

This policy paper combines the findings of an extensive, multimethodology empirical policy study carried out on behalf of the European Commission ${ }^{1}$ and targeting European Union Internet of Things (EU IoT) innovation clusters, with the most significant outcomes of the current debate around clusters to provide a concrete assessment of ways forward in cluster-related policy-making. The study explored drivers of creation and development of IoT clusters, their processes and dynamics, patterns of operations, and technological development, the policy priorities of clusters expectations.

\section{IoT, Security Challenges, and 5G Connectivity}

The accelerating development of the IoT is regarded as one of the major breakthroughs in Information and Communication Technologies (ICT) and considered a key enabler for technological solutions for society, citizens, enterprises and governments, and taking advantage of Big Data and Machine Learning techniques (Pang, 2013). It is defined as "sensors and actuators connected by networks to computing systems," in principle excluding intentional human input (Manyika et al., 2015). These systems can monitor or manage the status, functionality and actions of connected objects and machines and have the potential to radically change the way physical objects are embedded in and interact with their environment, taking advantage of data-driven decision making.

McKinsey Global Institute estimates a potential economic impact - including consumer surplus - of as much as $\$ 11.1$ trillion per year in 2025 for IoT applications in nine settings. The value created is heavily based on the interoperability between IoT systems and business-to-business (B2B) applications that can create more value than pure consumer applications. To realize the full potential from IoT applications, technology will need to continue to evolve, providing lower costs and more robust data analytics.

Ebersold confirms that the combined capabilities of IPv6 and parallel computing support the efficient and effective connection of 50-100 trillion objects. Both technologies provide the infrastructural support to monitor and activate connected devicesmaking the IoT a powerful enabler of "a cyberphysical system that connects computational processes and the physical world." Furthermore, uniting the physical and digital worlds has implications on organizational procedures, security and privacy of bodies and institutions that are developing IoT-based services and processes (Ebersold and Glass, 2015). The increased IoT security challenges are due to the ubiquitous nature of IoT systems and to the requirements on functionalities to be put in place (Mahmoud et al., 2015). The physical boundaries of enterprises and systems are disappearing, creating an open environment and a potentially limitless risk landscape (He et al., 2016).

5G is boosting the potential for IoT applications ( $\mathrm{Li}$ et al., 2018), further enabling responses to increasing numbers of connections, connected nodes, bandwidth, mass of data, security, and new standards and more complicated communication, device computational capabilities, driving the shift of IoT from infrastructure-driven to business-driven IoT applications. "The fast take up and roll-out of $5 G$ communications represents a potentially disruptive element in such a context. The increased data rate, reduced end-to-end latency, and improved coverage hold the potential to cater for even the most demanding of IoT applications in terms of communication requirements" (Palattella et al., 2016; Akpakwu et al., 2017).

\footnotetext{
${ }^{1}$ https://op.europa.eu/it/publication-detail/-/publication/61b2eebf-cecb-11e9-992f-01aa75ed71a1
} 
IoT systems raise questions about data security and privacy and in most organizations, taking advantage of the IoT opportunity will require leaders to truly embrace data-driven decision making. Kaska et al. (2019) have discussed the role of Huawei as a product of the Chinese national policy of technological superiority and as a global market leader in supplying $5 \mathrm{G}$ technologies. Chinese technology companies have grown to global market power and Huawei is exemplary of the country's technology policy: it is the largest global telecoms equipment manufacturer and the only player that can supply all the elements of a 5G network. In fact there has been no public evidence of significant vulnerabilities in Huawei technology and the authors recommend a coordinated response by governments to adopt a nuanced risk awareness and risk management approach. In their discussion, Kaska et al. (2019) recommend a graduated approach, as the one taken in some countries, where transparent oversight was guaranteed with through the establishment of a cooperation base.

\section{Innovation Clusters}

With respect to clusters, scholars have early on recognized the natural tendency of enterprises to aggregate (Porter, 1998), and how value chain integration and cooperative innovation in clusters lead to productivity gains and individual and aggregate competitive advantage through the productivity gains achieved. In communities with strong inter-personal relationships innovative activities are particularly favored and fact that economic and innovation activities are embedded in social activities makes them more successful and sustainable. Porter (2000) and Porter (1998b) specifies that "Clusters are geographic concentrations of interconnected companies and institutions in a particular field. Clusters encompass an array of linked industries and other entities important to competition. They include, for example, suppliers of specialized inputs such as components, machinery, and services, and providers of specialized infrastructure. Clusters also often extend downstream to channels and customers and laterally to manufacturers of complementary products and to companies in industries related by skills, technologies, or common inputs. Finally, many clusters include governmental and other institutions - such as universities, standards-setting agencies, think tanks, vocational training providers, and trade associations - that provide specialized training, education, information, research, and technical support." Clusters appear to facilitate self-reinforcing processes of innovation and growth (Capello, 1999) and through physical proximity spur virtuous interactions and enable collective learning mechanisms (Melachroinos and Spence, 2001; Storper and Venables, 2004). According to Krugman and Venables (1996) imperfectly competitive industries need intermediates to determine the creation of cost and demand linkages between firms and are conducive to industrial agglomeration, which is strongly influenced by economies of scale, by transport costs and trade barriers. Ellison and Glaeser (1997) confirm that firms' location decisions are highly sensitive to cost differences and that geographic concentration may largely be due to natural advantages (Ellison and Glaeser, 1999).

Classic Marshallian districts show the tendencies to agglomerate and cooperate and compete at the same time, depending on the activity.

The motivations and factors which determine the location of innovative industries and their clusters are highly variable (Moretti, 2012): in specific places and thick labor markets; specialized service providers; and knowledge spill overs keep the ecosystem together. It is observed that Venture Capitalists are still very local and they only consider financing companies that are located close to monitor and track their activities closely.

Innovative companies seek knowledge spill overs and they want to be close to their competitors to generate informal learning opportunities (Moretti, 2012). The proximity factor is also very important for scientists and inventors, for the same knowledge-related reason.

Clusters are very effective in supporting businesses sectors and ecosystems, in particular small and medium-sized enterprises (SMEs) and start-ups. They are also considered one of the key pillars of regional competitiveness, even if the measurement of their impacts and outcomes is prone to selection biases and sensitivity of definitions (van Oort and Thissen in Huggins and Thompson, 2017). Clustering is not sufficient, since "while organisations may benefit from local knowledge spill overs ... they may also need to consciously build non local 'pipelines' to tap int knowledge from outside the region", competing "in an environment that is simultaneously local and global." A growing base of evidence confirms that 
knowledge is increasingly flowing across geographic clusters, generating heightened global knowledge connectivity, and that networks and clusters need to keep abreast of knowledge emerging outside their respective regions not to run the risk of becoming inflexible and outdated (Huggins and Thompson, 2017).

This policy paper combines empirical, multimethodology research on IoT innovation clusters with the existing research on the agglomeration economy and business ecosystem studies. It presents an overview of the main IoT market trends, of the main IoT development domains, and on the location of main IoT innovation clusters in Europe (Section 1); the methods and classifications used for the research work (Section 2); the results of the analysis of IoT innovation clusters in Europe, their geographical distribution and the results of the surveying and case studies, challenges and drivers of operations, enabling factors, and success factors. The EU policy framework (Section 3); the discussion of results, including an overview and a review of cluster and cluster policy impacts (Section 5) and the conclusions of the study work (Section 6).

\section{Background and Literature Review}

\subsection{IoT market trends}

The worldwide spending on IoT is expected to reach $\$ 772$ billion by end of 2018 with a compound annual growth rate (CAGR) of 14.4\% through the 2017-2021 period (International Data Corporation - IDC, $2017^{2}$ ).

The analysis of the Total Addressable Market database by Transforma Insights ${ }^{3}$ indicates that at the end of 2019 there were 7.6 billion active IoT devices, to increase to 24.1 billion in 2030, a CAGR of $11 \%$.

The International Data Corporation (IDC) confirms that world-wide spending on IoT has been significantly impacted by the effects of the COVID-19 pandemic in 2020, although a back to doubledigit growth rebound is expected. The IDC update expects IoT spending to grow $8.2 \%$ year over year to $\$ 742$ billion in 2020 down from 14.9\% growth forecast in November 2019 and global IoT spending is expected to return to double-digit growth rates in 2021 with a compound annual growth rate (CAGR) of $11.3 \%$ between 2020 and 2024 .

In 2019, the total IoT market was worth US\$465 billion, which will rise to US\$1.5 trillion in 2030. Services, including connectivity, will account for $66 \%$ of investment. ${ }^{4}$

With 41.6 billion of connected IoT devices, and 79.4 zettabytes (ZB) of data by $2025,{ }^{5}$ IoT systems will be a major producer and consumer of data creating complex systems and critical infrastructure (energy, communications, mobility, and healthcare), with zero network latency, location awareness, immediate real-time insights, ${ }^{6}$ bandwidth, and lower operational costs. ${ }^{7}$

Statista shows the distribution of software developers for IoT with the highest incidence of custom system integrators and commercial independent software vendors rather than of providers of fully integrated solutions and systems (Figure 1).

\subsection{Agglomeration economies and IoT innovation clusters}

Industry clusters were originally discussed by Porter (1998a) in "The Competitive Advantage of Nations" and refer back to the underlying concept of agglomeration economies developed by Alfred Marshall in the early years of the twentieth century.

Porter affirms that cluster membership can generate individual and aggregate competitive advantage through productivity gains achieved through value chain integration and cooperative innovation. The strong inter-personal relationships are a driver of innovative activities embedding economic and innovation in social activities.

\footnotetext{
${ }^{2}$ IDC Worldwide IoT Semi-annual Spending Guide 2017.

${ }^{3}$ https://transformainsights.com

${ }^{4}$ ibidem.

${ }^{5}$ Worldwide Global DataSphere IoT Device and Data Forecast, 2019-2023. IDC.

${ }^{6}$ Internet of Things (IoT) Market Size, Share By Component, Platform, Solution, End-Use, and Regional Forecast, $2020-2027$. Fortune Business Insights. Report ID: FBI100307.

${ }^{7}$ Worldwide Global DataSphere IoT Device and Data Forecast, 2019-2023. IDC.
} 


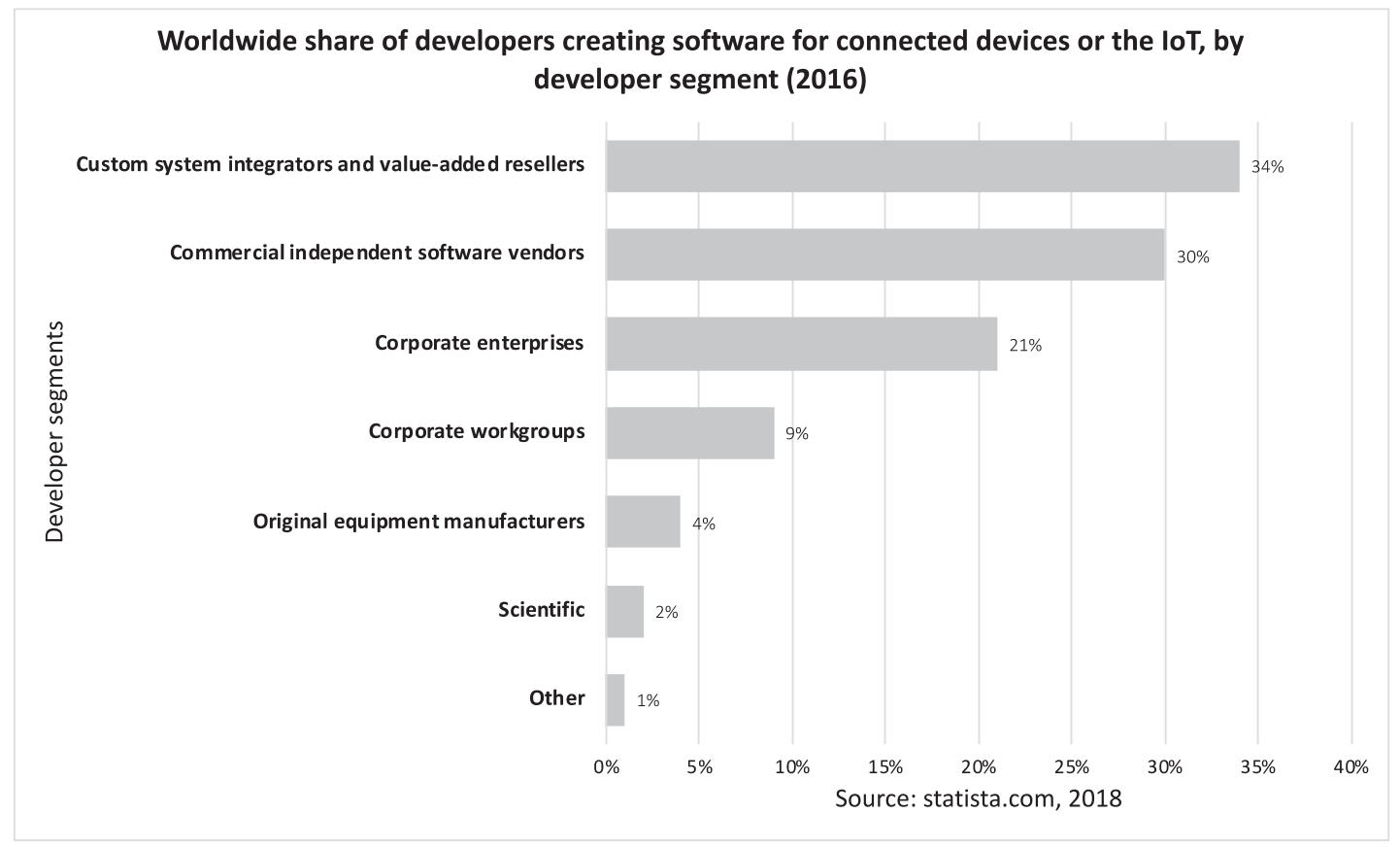

Figure 1. Software developers for connected Internet of Things (IoT) devices, by segment (2016).

Russell and Smorodinskaya (2018) consider innovation clusters as a sophisticated subvariety of innovation ecosystems, which rely on the agility of network relationships and the collaborative, nonhierarchic models of governance conducive to self-adaptability to change (Capello, 1999). They favor the creation of technological critical mass, relationships, opportunities, and economies of scale through selfreinforcing processes of innovation and growth (Capello, 1999) and collective learning mechanisms (Melachroinos and Spence, 2001; Storper and Venables, 2004).

"Innovations are the output of a knowledge creation process that is derived by the exchange of tacit and explicit knowledge," but cause-effect relationships, what determines which results and outcomes are variable (Ibrahim and Fallah, 2005).

The location of innovative activities is a conscious strategic decision of corporate executives (Ibrahim and Fallah, 2005). They assess the value of locating in a technological cluster and assess how these settings can be beneficial to the structuring of R\&D and innovation activities impacting on competitiveness. Merely by moving into a high-tech cluster a firm in effect becomes "larger," because it can draw on specialized local expertise of the ecosystem, business services, and venture capitalists (Moretti, 2012). Ferras-Hernandez and Nylund (2019) confirm that "innovation in innovation clusters is accelerated by the combined and multiplying action of several strengths which mutually reinforce each other." They propose that such accelerators are based on attraction, anticipation, rivalry, information, and interaction.

However, there is no theoretical framework that explains why the inclusion of a firm in a cluster enhances its innovativeness and Ibrahim and Fallah confirm that, even if firms in clusters have a higher innovative output, not much is known about the mechanisms of this relationship, even if belonging to a cluster is beneficial for a company (Porter, 1998b; Porter, 2000; Moretti, 2012; Andrienko, 2021).

\subsection{EU IoT policies}

The EU places the IoT among the high priorities of the digital single market. IoT is targeted by a number of horizontal policies: data protection, cybersecurity (Commission Staff Working Document, 2016a). The 
IoT merges physical and virtual worlds, creating smart environments and the European Commission actively cooperates with industry, organizations, and academic institutions in order to unleash the potential of the IoT technology across EU Member States and beyond (Commission Staff Working Document, 2016b). A potential obstacle for the achievement of a single market for the IoT is the capacity to handle a large diversity and very large volumes of connected devices and the need to securely identify them and be able to discover them so that they can be plugged into IoT systems (Commission Staff Working Document, 2020).

The EU appears to concentrate its efforts to support of concrete IoT Research and Innovation actions funded under Horizon 2020 or Horizon Europe. ${ }^{8}$ The programs support the development of advanced platform architectures for smart objects, embedded intelligence, and smart networks. Projects develop and validate innovative platform technologies and foster technology adoption through community- and business-building while creating at the same time a new vibrant IoT ecosystem. The European Commission has been working intensively on developing the right European IoT ecosystem together with key stakeholders and has launched a specific cluster of specific R\&D projects to tackle the issues of security and privacy and to foster trust in IoT solutions.

\section{Methods, Classifications, and Taxonomies}

The IoT innovation cluster study used an integrated set of qualitative and quantitative analytical approaches: (a) desk analysis of literature and databases and webscraping work providing data on scale and location of IoT innovation clusters in Europe; (b) a full-target direct survey of EU clusters; (c) a survey of businesses, research organizations, academic establishments, and public bodies engaged in IoT development; (d) 20 IoT cluster case studies, targeting each at least five of their members ${ }^{9}$; and (e) overall policy analysis for a synthesis and to elaborate practical recommendations for IoT development and cluster sustainability.

For the study in-depth, semi-structured interviews were conducted with managers from the six participating clusters. We also interviewed the managers of four other clusters (which did not participate in the main study) to gain a better understanding of the research context.

For the overall consistency of our approach three taxonomies used in the industry were adopted to conceptually guide the research questions: the quantitative and qualitative characterization of the IoT cluster ecosystem; drivers and enablers; critical success factors; and the contextual framework of development and operations and IoT technologies.

1. A classification of clusters:

- Technological communities, created around a specific technology.

- Research-driven clusters, which involve players around a research venture.

- Integration of ICT players and test-beds, originated from the need of enterprises to cooperate with user communities.

- Sector/industry-specific clusters, to address the needs of specific industrial areas.

- ICT cluster for sectoral development in a region, to boost the development and growth.

- Industrial districts in the classic conception of Marshall and Porter: physical places where firms and workers specialized in a main industry or value chain, ${ }^{10}$ work and develop.

\footnotetext{
${ }^{8}$ https://ec.europa.eu/digital-single-market/en/research-innovation-iot

${ }^{9}$ The case studies' selection has followed the geographical criterion in first instance and subsequently the criterion of application area.

10 "The value chain is defined very simply as a series of production tiers, each tier producing items that are substitutable in terms of the function they assume in a final product or service. This chain culminates in a specific product or service in which all of the value of components and processes has accumulated. The units of production in each tier of our value chain formulation are firms and organizations." https://www.oecd.org/sti/ieconomy/22572212.pdf
} 
2. IoT application areas are those fields in society, economy, and technology where IoT applications are integrated and deployed:

- Smart Living: implementations in the close environment for operation of devices.

- Smart Cities, using sensors and actuators embedded in technological solutions to improve the management of the urban environment.

- Smart Industry, implementing a ICT-driven network-centric approach for a high degree of flexibility in production, and to fine tune to customer needs ${ }^{11}$;

- Smart Environment, centered on the use of Green Computing and IT to develop intelligent systems for the optimization of natural resources and to protect the environment: Smart Forestry, Mining, Farming, and Food production.

- Smart Energy Systems for optimized achievable and affordable energy solutions. ${ }^{12}$

3. IoT enabling technologies, the building blocks of internet of things implementations:

- Authentication and Security, for system integrity and availability. ${ }^{13}$

- Artificial Intelligence and Machine Learning, for smarter actuations. ${ }^{14}$

- Sensors: data gathering from the physical environment to be used to perform predefined functions upon specific input. Smart sensors ${ }^{15}$ enable accurate automated collection of environmental data for monitoring and control mechanisms in a wide variety of environments. ${ }^{16}$ Wearables specifically refer to enabling human-related actions. ${ }^{17}$

- IoT Platforms and Middleware: hardware and software components to support IoT systems. ${ }^{18}$

- Broadband and Communications: high-capacity transmission, enabling an massive number of simultaneous messages. It represents the vital horizontal layer of the IoT implementation. The fast take up and roll-out of $5 \mathrm{G}$ will further boost the development of IoT. ${ }^{19}$

\subsection{The survey and the case study guidelines}

The online survey was designed on the basis of the research framework and questions, which secured the consistency of the researched themes and the complementarity of the responses. The survey had the purpose to explore the following aspects of clusters and their IoT and innovation activities: basic information on the cluster; establishment of the cluster; organizational information; key IoT challenges and opportunities: 5-year forecast; application domains and enabling technologies; cluster membership and cluster association; cluster fostering and hampering factors; cluster policy needs; cluster's development; cluster's composition; the main fostering and hampering factors of IoT development; services and infrastructures offered within the cluster; cluster's policy needs; and broader IoT Policy needs.

The case studies were designed using the research framework and questions to further explore and to gather additional explanatory information on survey outcomes, discussing the topics: basic information on the cluster; establishment of the cluster; cluster's development; cluster's composition; the main fostering and hampering factors to IoT cluster operation and development; services and infrastructures offered within the cluster; outcomes and impacts; cluster's policy needs; IoT policy needs; and overall assessment.

\footnotetext{
${ }^{11} \mathrm{https}: / /$ smartindustry.nl/voorbeeld-pagina/

$12 \mathrm{https} / / /$ www.researchgate.net/publication/317122110_Smart_Energy_and_Smart_Energy_Systems

$13 \mathrm{https} / / /$ www.verizon.com/about/sites/default/files/state-of-the-internet-of-things-market-report-2016.pdf

${ }^{14} \mathrm{https}$ :/www.forbes.com/sites/bernardmarr/2016/12/06/what-is-the-difference-between-artificial-intelligence-and-machinelearning/\#3a663ee82742

15 https://whatis.techtarget.com/definition/sensor

${ }^{16} \mathrm{https}: / /$ internetofthingsagenda.techtarget.com/definition/smart-sensor

${ }^{17} \mathrm{https} / / /$ pdfs.semanticscholar.org/57b7/240f0b2d1395c08c7dee868a4754510ba9be.pdf

$18 \mathrm{https}$ ://internetofthingsagenda.techtarget.com/definition/IoT-middleware-Internet-of-Things-middleware

${ }^{19} \mathrm{http} / / /$ www.broadbandcommission.org/Documents/Media\%20Corner\%20Files $\% 20$ and $\% 20$ pdfs/Broadband $\% 20 \mathrm{drives} \%$ 20the $\% 20$ Internet $\% 20$ of $\% 20$ Things.pdf
} 
Table 1. Survey respondents by type declaring cluster membership

\begin{tabular}{lccc}
\hline & Declared cluster membership & Total respondents & $\begin{array}{c}\text { Percentage of respondents } \\
\text { belonging to clusters }\end{array}$ \\
\hline Businesses & 246 & 597 & $41.21 \%$ \\
RTOs & 97 & 134 & $72.39 \%$ \\
Academic institutions & 67 & 153 & $43.79 \%$ \\
Other actors & 95 & 114 & $83.33 \%$ \\
Not specified & - & 171 & $43.20 \%$ \\
& 505 & 1,169 & \\
\hline
\end{tabular}

RTOs, research and technology organizations.

Source: IoT Innovation Cluster Study. ${ }^{20}$

\subsection{Overview of results of the field research}

The desk research had identified 389 EU IoT innovation clusters and, associated to them, about 12,000 cluster member companies. In fact, it is mostly impossible to separate IoT-specific data from the more general ICT data, IoT-dedicated personnel and general ICT staff, IoT-specific R\&D investment, since no separate records are usually kept.

The direct survey was one of the sources of cluster data to build a large database of diversified IoT innovation clusters in the 28 European Member States. It targeted about 22 clusters, with 1169 participating IoT players, partly overlapping with those included in the desk research. Table 1 shows the stratification of respondents to the direct survey, which targeted the total universe of potential IoT industrial actors.

The overall sample of this survey was 3,686 bodies, split between businesses, research and technology organizations (RTOs), and Academia. The survey yielded a response of 1169 questionnaires, stratified as follows:

Over $40 \%$ of survey participants declared the affiliation with a cluster and confirms that businesses tend to agglomerate with other innovative firms and into dynamic and fast-developing ecosystems with thick talent markets and a rich service offering, as confirmed by Moretti (2012). ${ }^{21}$

\section{The Analysis of IoT Innovation Clusters}

Each section of this paragraph provides information and findings about the research undertaken, touching upon their different characteristics, behaviors, and dynamics.

\subsection{The geographical distribution}

The cluster landscape in Europe is constantly developing, the present mapping provides a picture at a given time and IoT cluster numbers and locations are expected to change. Figure 2 shows the distribution of clusters in 26 EU Member States that have at least one clusters. Reasons for such distribution may be relate to public policy for industry and research and innovation, regional policies, EU policies, characteristics of industry, and so on.

The full list of clusters reviewed in this study is in the annex.

\subsection{Drivers for the establishment of innovation clusters}

The surveys identified the mainstream trends while the interviews gathered additional explanatory details defined the fundamental drivers of the set-up of innovation clusters. Often the creation IoT innovation

\footnotetext{
${ }^{20} \mathrm{https} / /$ ec.europa.eu/digital-single-market/en/internet-of-things/clusters

${ }^{21}$ Moretti, Enrico. The New Geography of Jobs. Mariner Books 2013. Chapter "Forces of Attraction."
} 


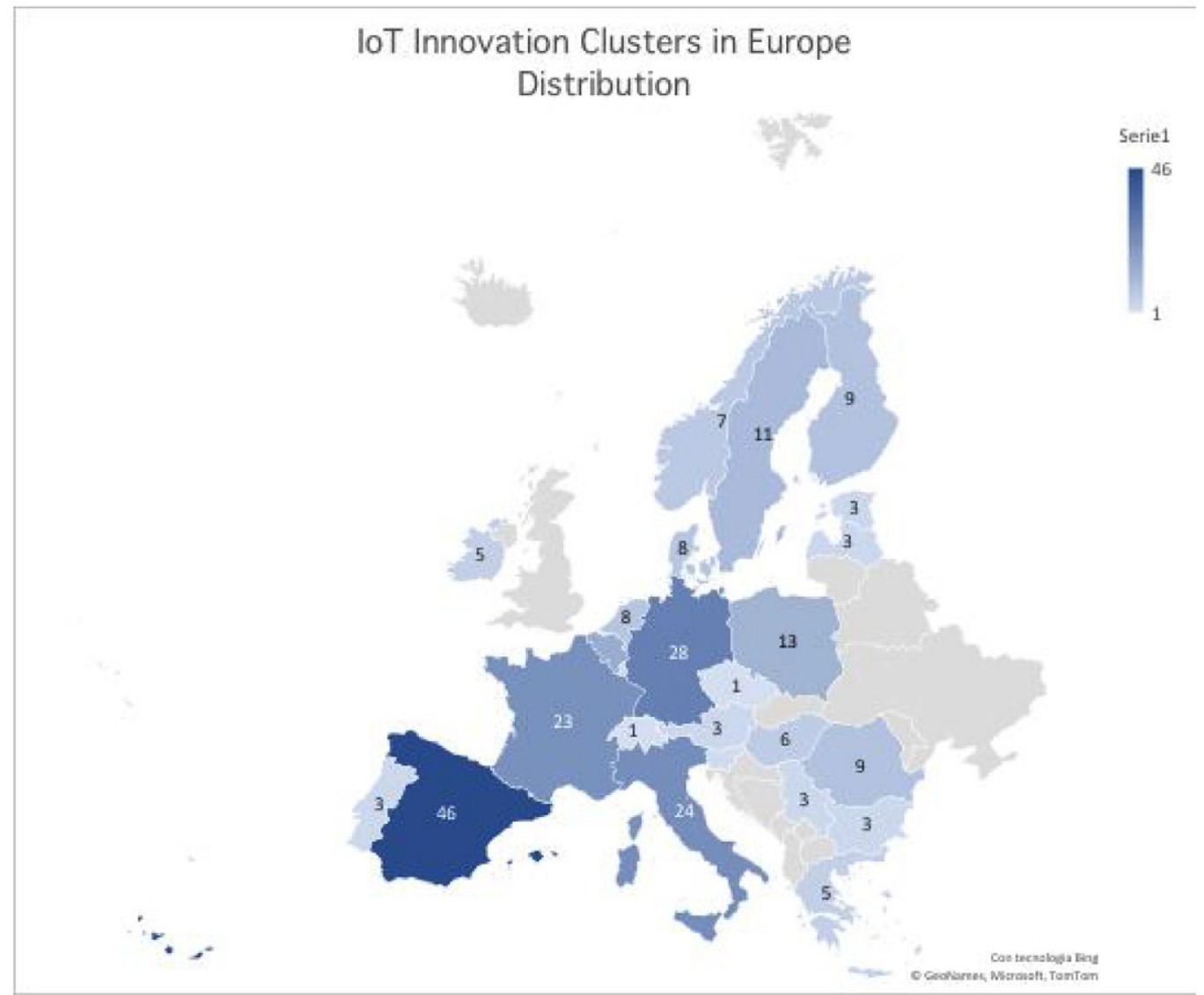

Figure 2. Cluster and cluster types per country.

Source: IoT Innovation Cluster Study. ${ }^{22}$

clusters is the response to industrial and sectoral crises, of that large enterprises or in response to more general economic downturns, other clusters were launched as EU-supported Public Private Partnerships for specific purposes, such as Industry 4.0 and the Future Internet. There are several public policy initiatives for regional, industrial, and innovation support, which launched clusters, demonstrating that strong formal and informal institutions are an important constituent of innovation ecosystems. Policymakers also put in place soft measures for trust-building and to establish informal institutions facilitating innovation (Speldekamp et al., 2020). In fact, the case studies confirm that public bodies are essential stakeholders and contributors, however, they are by no means crucial for the cluster's financial sustainability (a) because of the unpredictability of funding and (b) because of the fundamental incompatibility of the main current principles of publicly funded project-work with the core operational patterns of innovation clusters.

Clusters believe that applying for project-related funding is not appropriate for clusters because of the potential conflict between the specific objective of the project work and the objectives of the cluster, its mission and life cycle and their relatively short time-frame. Furthermore, in none of the cases studies emerged any expectation to ensure sustainability by means of public program funds.

\footnotetext{
${ }^{22}$ https://ec.europa.eu/digital-single-market/en/internet-of-things/clusters
} 


\subsection{Cluster participants and their roles}

The IoT innovation cluster case studies determined type and role of actors in and interacting with IoT innovation clusters. Several clusters were initiated and promoted by large multinational companies (LMCs) or large RTOs and universities. Observation shows that the formation of clusters is essentially a "bottom up" process, with some exceptions where cluster creation was supported by national or regional government agencies, which provided resources and the mentioned framework for trust building. Some of the case studies show that large enterprises and RTOs acting as initiators of innovation clusters have in practice "faded out". In other cases, in particular, some cluster within the Industry 4.0 strategy were merged in a hope to improve sustainability.

\subsubsection{Administrations and public institutions}

The contribution of public institutions to the mid-term sustainability of clusters is questioned. They are certainly effective connecting the cluster to the region and facilitate the policy discourse and relevant regulations.

These issues associated with public intervention in innovation clusters are confirmed by Duranton (2011) "First, clustering is not a choice variable that policy-makers can easily manipulate. Second, this intermediate outcome is only weakly related to the final prosperity objectives that local policy-makers should be interested in." In the same line, Martin and Mayneris (2011) have confirmed that French cluster policies have been unable to reverse the relative decline of total factor productivity in firms targeted by such policies.

\subsubsection{SMEs and start-ups}

Clusters are considered the natural aggregators and supporters of SMEs and start-ups. Case studies confirm that SMEs are key innovation players and cluster membership strengthens their innovative capabilities, productivity, and competitiveness (Makedos, 2014). There is a significant difference between the innovative capacity of SMEs and that of large enterprises, however, the former have some structural limitations related to their size, as concerns their operational critical mass and financial scale and their capability to absorb knowledge.

The participation in a cluster makes SMEs more effective and successful in fundraising, in absorbing new knowledge and create new potential for value added, leveraging their natural flexibility to be more easily integrated into cluster value chains. Accordingly, scholars emphasize that businesses can selfdevelop in clusters and cooperate either with one another or with university institutions and research centeres, with the objective aim to grow larger and become international (Porter, 1998a).

Desk research of the IoT innovation clusters study delivered relatively little information about the startups dynamics. On the contrary, the case studies provided for the interesting experiences of the German VDC cluster ${ }^{23}$ that includes 98 start-ups among the 250 members. The setup of this cluster provides for reduced fees and start-up dedicated programs and activities, while the Finnish FIIF cluster ${ }^{24}$ provides start-ups services free of charge, drawing the resources from the fees of cluster members. Start-ups are particularly dynamic, active, and fragile enterprises and need cluster set-ups that are compatible with their specific structural and operational characteristics and they are normally unable to allocate significant resources to non-core expenditures such as cluster fees.

Literature confirms that start-ups are a key driver of the development of IoT technologies as flexible young companies working on breakthrough innovation and application development and constitute a key factor for accelerating value chain dynamics, as well as key accelerator of innovation, economic growth, and job creation (Calvino et al., 2016).

According to the analysis of quantitative data sources, the countries with the highest number of startups active in IoT clusters are in the UK, in France, Germany, Spain, and Italy.

\footnotetext{
${ }^{23} \mathrm{https} / / / \mathrm{www} . v \mathrm{dc}-$ fellbach.de

${ }^{24} \mathrm{https}: / /$ fiif.fi
} 
Table 2. Number of IoT cluster members by type (2012-2017)

\begin{tabular}{lccc}
\hline Number of different actors in IoT clusters $(n=22)$ & 2012 & 2017 & Delta \\
\hline Universities & 61 & 94 & $54.1 \%$ \\
RTOs & 28 & 72 & $157.1 \%$ \\
Businesses (Total) & 591 & 789 & $33.5 \%$ \\
$\quad$ System integrators & 203 & 277 & $36.5 \%$ \\
Demand aggregators & 20 & 44 & $120.0 \%$ \\
Research service providers & 56 & 70 & $25.0 \%$ \\
Component developers and producers & 164 & 179 & $9.1 \%$ \\
$\quad$ Software developers & 148 & 219 & $48.0 \%$ \\
Public Sector organizations & 15 & 32 & $113.3 \%$ \\
Associations & 17 & 23 & $35.3 \%$ \\
Overall & 712 & 1010 & $41.9 \%$ \\
\hline
\end{tabular}

Abbreviations: IoT, Internet of Things; RTOs, research and technology organizations.

Source: IoT Innovation Cluster Study. ${ }^{25}$

\subsection{Dynamics of cluster membership and composition}

The study has investigated how cluster characteristics changed between 2012 and 2017 and initially focused on the dynamics of cluster membership as emerging from the survey. Table 2 shows the highest increase in the category "RTOs," enterprise members increased by average 33\%, with high peaks for demand aggregators $(+120 \%)$ and software developers $(+48 \%)$, while component developers and producers only showed a modest increase. Public sector organizations increased significantly $(+113 \%)$, as well as universities $(+54 \%)$.

These survey results show the positive attraction-effect of clusters. This may explain the relatively limited increase of cluster membership in the category "component developers and producers," in respect to other categories of other ICT businesses.

\subsection{Core cluster activities in innovation, services, and infrastructures}

The survey results confirm that IoT clusters are essentially business- and technology-oriented service organizations and deliver four main types of services to their members:

1. Organizational, networking, and market services.

2. Technical and technological assessment and scouting services for knowledge sharing.

3. Application services with the specific purpose to develop and integrate and test code.

4. Other ancillary support services to the technological, innovation, and market process.

The majority of IoT innovation clusters participating in the survey provides technology development and technology integration services to enterprises (Table 3). Less than half of the clusters delivers skillstargeted training and financial services, venture capital, and private equity.

Only a limited number of clusters provides services for grant applications, services for start-up mentoring and networking and matchmaking events, confirming that IoT innovation clusters are mainly oriented toward application and development.

With respect to technological infrastructures and cooperation platforms, the majority of IoT innovation clusters have indicated that they provide facilities for technology development and for the integration of technologies, as well as testing facilities, all oriented toward application development (Table 4). Other, nontechnology support facilities are less frequently provided by IoT clusters.

\footnotetext{
${ }^{25}$ https://ec.europa.eu/digital-single-market/en/internet-of-things/clusters
} 
Table 3. Cluster services to IoT firms

IoT innovation cluster services for enterprises $(n=19)$

Technology development

Technology integration

Skills-targeted training

Financial services, VC, private equity

Grants for collaborative R\&D projects

Abbreviations: IoT, Internet of Things; VC, venture capital.

Source: IoT Innovation Cluster Study. ${ }^{26}$

Table 4. Cluster Infrastructures and platforms made available to IoT firms

IoT innovation cluster infrastructures for enterprises $(n=19)$

Facilities for technology development

Facilities for technology integration

R\&D and testing facilities

Open science, innovation, and knowledge transfer

Abbreviation: IoT, Internet of Things.

Source: IoT Innovation Cluster Study. ${ }^{27}$

Table 5. Weight of IoT technologies in the organization offering

\begin{tabular}{lcrr}
\hline IoT technologies in the organization offering & 2012 & 2017 & \\
\hline Authentication and security & $12.3 \%$ & $11.8 \%$ & $-0.5 \%$ \\
Artificial intelligence and machine learning & $7.5 \%$ & $11.1 \%$ & $3.6 \%$ \\
Wearables & $10.2 \%$ & $16.3 \%$ & $6.1 \%$ \\
Sensors & $12.0 \%$ & $16.6 \%$ & $4.5 \%$ \\
IoT platforms and middleware & $14.3 \%$ & $19.6 \%$ & $5.3 \%$ \\
Broadband and telecommunications & $24.0 \%$ & $21.4 \%$ & $-2.5 \%$ \\
\hline
\end{tabular}

The survey checked the IoT technologies in the cluster service offering and its variations between 2012 and 2017 as a proxy for their weight in respect to the market (Table 5).

The average weight of the different IoT application domain and their variation in the 5 years previous to the survey was estimated by the innovation clusters taking part in the survey (Table 6).

\footnotetext{
${ }^{26} \mathrm{https} / /$ ec.europa.eu/digital-single-market/en/internet-of-things/clusters

27 ibidem.

${ }^{28}$ ibidem.
} 
Table 6. Weight of IoT application domains in the organization offering

\begin{tabular}{llrr}
\hline IoT application domains in the organization offering & 2012 & 2017 & \\
\hline Smart Living & $17.4 \%$ & $16.9 \%$ & $-0.5 \%$ \\
Smart Cities & $14.0 \%$ & $20.9 \%$ & $6.9 \%$ \\
Smart Industry & $20.3 \%$ & $25.2 \%$ & $4.9 \%$ \\
Smart Environment & $5.9 \%$ & $10.2 \%$ & $4.3 \%$ \\
Smart Energy & $12.5 \%$ & $15.9 \%$ & $3.4 \%$ \\
\hline
\end{tabular}

Abbreviation: IoT, Internet of Things.

Source: IoT Innovation Cluster Study. ${ }^{29}$

Table 7. Change of weight of IoT enabling technologies by actor type

\begin{tabular}{llll}
\hline 2012-2017 & Companies & Universities & RTOs \\
\hline Authentication and security & + & ++ & --- \\
AI and machine learning & ++ & +++ & +++ \\
Wearables & +++ & ++++ & +++ \\
Sensors & ++++ & ++++ & +++ \\
IoT platforms and middleware & + & ++++ & ++++ \\
Broadband and telecommunications & --- & \\
& & \\
Coding & ++++ & \\
Very high increase & +++ & \\
High increase & ++ & \\
Moderate increase & + & \\
Increase & - & \\
Decrease & -- & \\
Moderate decrease & --- & \\
Hight decrease & --- & \\
Very high decrease & & \\
\hline
\end{tabular}

Abbreviations: IoT, Internet of Things; RTOs, research and technology organizations.

Source: IoT Cluster Study. ${ }^{30}$

\subsection{IoT cluster members' view on enabling technologies and application domains}

The survey included a number of judgmental questions, based on a quantitative scale, to weigh IoT enabling technologies. Cluster members were asked to assign weights to technologies and their changes in the 5 years before 2017, as shown in Table 7 on such changes in weight of IoT enabling technologies. The tables synthesize the opinions expressed by IoT innovation cluster members on the increase of weight of specific enabling technologies in the preceding 5 years coding minuses $(-)$ and pluses $(+)$ : the minuses range from very high decrease to decrease, the pluses from increase to very high increase.

Following the same approach, the survey targeted the different application domains (Table 8) and inquired about the weights and variations.

\subsection{IoT Cluster operations: challenges, drivers, and impediments}

Innovation clusters and their IoT activities develop in complex environments where contradictory forces may interplay. These dynamics challenge the design of strategies and activities and how value added is

\footnotetext{
29 ibidem.

30 ibidem.
} 
Table 8. Change of weight of IoT application domains by actor type

\begin{tabular}{llll}
\hline 2012-2017 & Companies & Universities & RTOs \\
\hline Smart living & --- & ++++ & ---- \\
Smart cities & ++ & ++++ & +++ \\
Smart industry & ++ & +++ & ++++ \\
Smart environment & +++ & +++ & ++++ \\
Smart energy & ++ & & +++ \\
& & & \\
Coding & & & \\
Very high increase & ++++ & \\
High increase & +++ & \\
Moderate increase & ++ & \\
Increase & + & \\
Decrease & - & \\
Moderate decrease & -- & \\
Hight decrease & --- & \\
Very high decrease & ---- & \\
\hline
\end{tabular}

Abbreviations: IoT, Internet of Things; RTOs, research and technology organizations.

Source: IoT Cluster Study. ${ }^{31}$

created for their heterogenous set of members and stakeholders, with their different needs, and developing them as an innovation community.

One of the main tests for innovation clusters is to balance sustained information sharing with the need to safeguard intellectual property rights and guarantee competition-related confidentiality, building trust, and fostering cooperation among their members. Organizations of different size that are associated to innovation clusters likely operate according to different patterns and rules. Large enterprises leverage their critical mass of research, innovation, and implementation capacity, but require rigid procedures to operate. Small and medium enterprises, and start-ups, on the contrary, have completely different needs and approaches, much less critical mass and a more flexible approach. Cooperation between the different types may require adjustments and harmonization and organizational and strategic tuning, taking into account the even more critical position of start-ups, who often face "tightness" of human, organizational, and financial resources.

Clusters need to have shared processes in place to guarantee and regular strategic orientation performance assessment and operational readjustment.

Surveys provide the answers of respondents on the specific drivers of IoT development in innovation clusters, in (Table 9) they are ranked in decreasing order. Solving data protection and privacy issues and fostering user acceptance are considered the most important drivers, clustering research activities, clustering industrial activities and developing implementation practices are considered the least important drivers.

The balance was computed between the different cluster factors qualified as drivers or impediments, the former compensating the latter (Table 10). Clearly, negative balances show that the relevant factor is considered more a driver than an impediment. It should also be considered that unaddressed drivers are very likely to become impediments.

\subsection{IoT enabling factors related to the economic and societal ecosystem}

The ecosystem factors were discussed in the case studies, where a strong link was established with the general economic and sectoral trends and to the ecosystem they operate in. Table 11 summarizes the inputs

\footnotetext{
${ }^{31}$ ibidem.
} 
Table 9. The key drivers to IoT development for all respondents $(\mathrm{n}=1,169)$

\begin{tabular}{|c|c|c|c|c|c|c|}
\hline & $\begin{array}{c}\text { Not } \\
\text { answered }\end{array}$ & $\begin{array}{l}\text { Not at } \\
\text { all } \\
\text { relevant }\end{array}$ & $\begin{array}{l}\text { Somewhat } \\
\text { not } \\
\text { relevant }\end{array}$ & $\begin{array}{c}\text { Somewhat } \\
\text { relevant }\end{array}$ & $\begin{array}{l}\text { Highly } \\
\text { relevant }\end{array}$ & \\
\hline $\begin{array}{l}\text { Solving data protection and } \\
\text { privacy issues }\end{array}$ & $9.30 \%$ & $0.00 \%$ & $2.10 \%$ & $19.60 \%$ & $69.10 \%$ & $100 \%$ \\
\hline Fostering user acceptance & $3.10 \%$ & $0.60 \%$ & $2.50 \%$ & $25.20 \%$ & $68.60 \%$ & $100 \%$ \\
\hline $\begin{array}{l}\text { An appropriate level of demand } \\
\text { for applications }\end{array}$ & $6.10 \%$ & $0.00 \%$ & $4.10 \%$ & $28.20 \%$ & $61.60 \%$ & $100 \%$ \\
\hline $\begin{array}{l}\text { Developing practices of } \\
\text { technology integration }\end{array}$ & $10.10 \%$ & $0.00 \%$ & $5.40 \%$ & $33.60 \%$ & $51.00 \%$ & $100 \%$ \\
\hline $\begin{array}{l}\text { Make available regulatory } \\
\text { solutions }\end{array}$ & $6.30 \%$ & $1.30 \%$ & $3.80 \%$ & $40.50 \%$ & $48.10 \%$ & $100 \%$ \\
\hline $\begin{array}{l}\text { An appropriate supply of } \\
\text { solutions and technology } \\
\text { availability }\end{array}$ & $7.40 \%$ & $0.80 \%$ & $3.10 \%$ & $41.50 \%$ & $47.30 \%$ & $100 \%$ \\
\hline $\begin{array}{l}\text { A appropriate level of diffusion } \\
\text { of data processing } \\
\text { technologies (algorithms) }\end{array}$ & $8.60 \%$ & $0.80 \%$ & $4.90 \%$ & $39.20 \%$ & $46.50 \%$ & $100 \%$ \\
\hline $\begin{array}{l}\text { An appropriate level of data } \\
\text { capturing technologies }\end{array}$ & $8.00 \%$ & $0.80 \%$ & $5.60 \%$ & $39.60 \%$ & $46.00 \%$ & $100 \%$ \\
\hline $\begin{array}{l}\text { Widespread open innovation } \\
\text { and cooperative innovation }\end{array}$ & $4.20 \%$ & $0.00 \%$ & $8.40 \%$ & $42.20 \%$ & $45.10 \%$ & $100 \%$ \\
\hline $\begin{array}{l}\text { Development of } \\
\text { implementation practices }\end{array}$ & $6.30 \%$ & $1.30 \%$ & $7.50 \%$ & $42.80 \%$ & $42.10 \%$ & $100 \%$ \\
\hline $\begin{array}{l}\text { Clustering of industrial } \\
\text { activities }\end{array}$ & $5.70 \%$ & $0.00 \%$ & $9.30 \%$ & $48.60 \%$ & $36.40 \%$ & $100 \%$ \\
\hline Clustering of research activities & $5.10 \%$ & $0.00 \%$ & $10.50 \%$ & $54.90 \%$ & $29.60 \%$ & $100 \%$ \\
\hline
\end{tabular}

Abbreviation: IoT, Internet of Things.

Source: IoT Innovation Cluster Study. ${ }^{32}$

of innovation cluster managers and members on what the factors, which affect IoT cluster sustainability and performance.

Table 11 presents the logical connection between the enabling factors discussed, with its specification and with the assessment of the impact expected on IoT innovation clusters.

Column one describes the enabling factor, column two provides an additional specification of the factors and column three elaborates on the impacts.

\subsection{Cluster-specific success factors}

The IoT cluster case studies focused on specific success factors, which affect their achievements, the recognition by its users, their ability to develop and their economic sustainability: financing, funding, and economic balance; strategic best practices; operational and management best practices; and technology and application-related best practices.

The variability of innovative performance and cluster could be related to the heterogeneity of cluster life cycles, each one influenced by the triggering factors which intervene in the local system's genesis and in its evolution-exhaustion, which refers to the factors explaining the decline and pathology of clusters (Lazzeretti et al., 2019).

\footnotetext{
32 ibidem.
} 
Table 10. The computed balance of responses on drivers and impediments to IoT development for all respondents $(\mathrm{n}=1,169)$

\begin{tabular}{|c|c|c|c|c|c|c|}
\hline & $\begin{array}{c}\text { Not } \\
\text { answered }\end{array}$ & $\begin{array}{l}\text { Not at } \\
\text { all } \\
\text { relevant }\end{array}$ & $\begin{array}{l}\text { Somewhat } \\
\text { not } \\
\text { relevant }\end{array}$ & $\begin{array}{l}\text { Somewhat } \\
\text { relevant }\end{array}$ & $\begin{array}{l}\text { Highly } \\
\text { relevant }\end{array}$ & \\
\hline $\begin{array}{l}\text { Solving data protection and } \\
\text { privacy issues }\end{array}$ & $-3.00 \%$ & $0.30 \%$ & $-0.70 \%$ & $1.90 \%$ & $1.40 \%$ & $0 \%$ \\
\hline Fostering user acceptance & $4.30 \%$ & $-0.60 \%$ & $1.70 \%$ & $-0.60 \%$ & $-4.70 \%$ & $0 \%$ \\
\hline $\begin{array}{l}\text { An appropriate level of demand } \\
\text { for applications }\end{array}$ & $5.50 \%$ & $1.40 \%$ & $-2.60 \%$ & $5.10 \%$ & $-9.40 \%$ & $0 \%$ \\
\hline $\begin{array}{l}\text { Developing practices of } \\
\text { technology integration }\end{array}$ & $-5.00 \%$ & $0.00 \%$ & $0.60 \%$ & $0.70 \%$ & $3.80 \%$ & $0 \%$ \\
\hline $\begin{array}{l}\text { Make available regulatory } \\
\text { solutions }\end{array}$ & $3.40 \%$ & $-0.50 \%$ & $1.80 \%$ & $-3.70 \%$ & $-1.10 \%$ & $0 \%$ \\
\hline $\begin{array}{l}\text { An appropriate supply of } \\
\text { solutions and technology } \\
\text { availability }\end{array}$ & $-0.50 \%$ & $-0.80 \%$ & $2.60 \%$ & $13.70 \%$ & $-15.10 \%$ & $0 \%$ \\
\hline $\begin{array}{l}\text { A appropriate level of diffusion } \\
\text { of data processing } \\
\text { technologies (algorithms) }\end{array}$ & $3.40 \%$ & $1.40 \%$ & $-1.60 \%$ & $2.10 \%$ & $-5.20 \%$ & $0 \%$ \\
\hline $\begin{array}{l}\text { An appropriate level of data } \\
\text { capturing technologies }\end{array}$ & $2.60 \%$ & $-0.80 \%$ & $4.00 \%$ & $-3.10 \%$ & $-2.70 \%$ & $0 \%$ \\
\hline $\begin{array}{l}\text { Widespread open innovation } \\
\text { and cooperative innovation }\end{array}$ & $17.50 \%$ & $2.20 \%$ & $6.80 \%$ & $-16.10 \%$ & $-10.30 \%$ & $0 \%$ \\
\hline $\begin{array}{l}\text { Development of } \\
\text { implementation practices }\end{array}$ & $-1.60 \%$ & $-1.30 \%$ & $-2.80 \%$ & $3.00 \%$ & $2.60 \%$ & $0 \%$ \\
\hline $\begin{array}{l}\text { Clustering of industrial } \\
\text { activities }\end{array}$ & 8.20 & 1.4 & $7.40 \%$ & 1.4 & $-1 \varepsilon$ & $0 \%$ \\
\hline Clustering of research activities & $9.20 \%$ & $3.60 \%$ & $16.30 \%$ & $-19.10 \%$ & $-9.90 \%$ & $0 \%$ \\
\hline
\end{tabular}

Abbreviation: IoT, Internet of Things.

Source: IoT Innovation Cluster Study. ${ }^{33}$

The following paragraphs discuss the success factors and the associated subfactors.

\subsubsection{Financing and funding}

IoT innovation cluster sustainability is a core theme and affects the continuity of services, the strategic perspective and the actual ability to sustained development and operations. Some of the prevailing funding models are not conducive to stability of resources and the critical issues emerging from the case studies concern:

1. The set-up of the initial funding cluster grant, which may be sufficient for the start-up phase, after which fees and other financial resources shall become available and ensure the sustainability of the undertaking. It happens frequently that the grant is not renewed.

2. The support by regional development policies, in particular from EU, national, and regional local bodies for the start-up phase and launch period but then are reduced and halted.

3. The subscription of membership fees, be it industry-driven or developing around an open source project or platform, closely connected to the real value of member services.

\footnotetext{
33 ibidem.
} 
Table 11. Framework and ecosystem factors and their impact on IoT clusters

\begin{tabular}{|c|c|c|}
\hline Factor & Specification & Impact on IoT clusters \\
\hline \multirow{3}{*}{$\begin{array}{l}\text { The general societal framework, } \\
\text { economic dynamics, } \\
\text { endogenous and exogenous } \\
\text { shocks }\end{array}$} & $\begin{array}{l}\text { Overall economic performance, in } \\
\text { terms of demand, supply, and } \\
\text { inflation }\end{array}$ & $\begin{array}{l}\text { Operation, performance, } \\
\text { and sustainability of IoT }\end{array}$ \\
\hline & Rules and policies & $\begin{array}{l}\text { Operation and } \\
\text { performance, user } \\
\text { acceptance }\end{array}$ \\
\hline & Taxes & $\begin{array}{l}\text { public budgets available } \\
\text { for public research, } \\
\text { development, and } \\
\text { innovation }\end{array}$ \\
\hline Technology Supply & $\begin{array}{l}\text { The availability of solutions and } \\
\text { technology, and more in general the } \\
\text { dynamics of the innovation } \\
\text { pipeline }^{\text {a }}\end{array}$ & $\begin{array}{l}\text { Response to demand, } \\
\text { quality, and } \\
\text { effectiveness of } \\
\text { solutions }\end{array}$ \\
\hline Demand & $\begin{array}{l}\text { level and critical mass of user demand, } \\
\text { which depends on the above } \\
\text { framework factors as well as from } \\
\text { the understanding, innovative } \\
\text { attitude, and absorptive capacity of } \\
\text { IoT users }\end{array}$ & $\begin{array}{l}\text { Output, innovation, } \\
\text { sustainability of the } \\
\text { ecosystem as a whole }\end{array}$ \\
\hline Quality of the ecosystem & $\begin{array}{l}\text { The level of IT sector development } \\
\text { and on the combination of different } \\
\text { ICT components }\end{array}$ & $\begin{array}{l}\text { Quality of supply of } \\
\text { solutions }\end{array}$ \\
\hline $\begin{array}{l}\text { Policy support at national or } \\
\text { regional level }\end{array}$ & $\begin{array}{l}\text { Legal, regulatory and industrial policy } \\
\text { framework and support }\end{array}$ & $\begin{array}{l}\text { Operation and } \\
\text { performance, user } \\
\text { acceptance }\end{array}$ \\
\hline $\begin{array}{l}\text { Ability of cities to work with } \\
\text { open data }\end{array}$ & $\begin{array}{l}\text { major issue with data, which can be } \\
\text { heterogenous or lacking }\end{array}$ & $\begin{array}{l}\text { IoT applications for Smart } \\
\text { Cities and Smart } \\
\text { Environment }\end{array}$ \\
\hline
\end{tabular}

Abbreviations: ICT, Information and Communication Technologies; IoT, Internet of Things; IT, information technology.

${ }^{a}$ The innovation pipeline is the conceptual sequence which links knowledge creation with market application and sales. The sequence is not linear and has all the necessary iterations to ensure the appropriate linking of all the stages with the knowledge transfer process.

Source: IoT Innovation Cluster Study. ${ }^{34}$

4. The availability of contributions by universities and research organizations, typically not very stable and tends to be related to projects.

5. Funded project work - several clusters engage in project work to sustain their structural costs, most of all of personnel. This type of funding may be subject to major fluctuations, with impacts on stability and on resources for core strategic activities. Clusters confirm that if project funding becomes dominating, the economic risk level for the cluster organization increases and therefore several clusters do not pursue these funding sources.

\subsubsection{Strategic and operational good practices}

The most successful case study IoT innovation clusters have moved from a member-driven push approach to a "large clubs," horizontal model, mainly focusing on sustained, and sustainable networking with

\footnotetext{
34 ibidem.
} 
members and stakeholders. Strategically, several clusters are becoming part of wider national and international networks, while still developing the connections to the local industry. Internationalization is often a high priority.

The IoT cluster good practices emerging from the study are market-related and include:

1. The regular revision, adjustment, and relaunch of the cluster strategy and economic and operational positioning and the monitoring of relevant ecosystem.

2. Structured cluster processes, which are seen as a positive practice and make the activities clearer and more transparent.

3. Technological assessment linked to cluster strategies and operations and supporting member and stakeholder research and innovation, focusing on short- and long-term technological developments and assessment of the cluster's positioning in terms of offering, role, skills and competencies, and networking.

4. IoT clusters focus on concrete, close-to-the-market applications, while they tend not to be involved in technology policy research.

IoT innovation cluster case studies are interested in policies and regulations only insofar they directly affect their activities and members. Beyond this pragmatic approach, researchers affirm that it is important to strengthen cluster ecosystems, ensuring that governments establish an appropriate regulatory framework (Xie et al., 2016).

According to Vernay et al. (2018), cluster policy may lead to paradoxical results due to the conflicting goals of developing a local economy and make the cluster economically independent over time and at the same time ensuring that policy and accountability goals are respected. Another aspect concerns government-supported top-down clusters, which may not lead to the sense of belonging to the cluster necessary to unleash its full potential and develop the social capital and the necessary shared vision. A potential negative impact of cluster policy on the performance of firms in sectors not directly and primarily addressed by public programs and targeted by subsidies (Audretsch et al., 2019).

\subsubsection{Technology and application-related good practices}

A number of cluster key issues are related to the deployment of IoT applications, within themes such as data silos, data formats and ontologies, as well as data capture and processing and output, with the relevant nontechnical implications:

1. Data silos, in the case that data are not shared among different vertical application sectors or even within the same domain.

2. Homogenisation of data formats and semantics as well as data ontologies.

3. Management of trust and data sovereignty.

4. Technologies to process digital content.

5. IoT risk assessment and management.

6. Individual and organizational competencies, skills, and expertise.

Case studies confirm that clusters that address these issues systematically increase their potential to advance the development and adoption of IoT applications and improving the innovative performance of clusters and the players that work within them.

\subsection{The $E U$ policy framework and the measures from the perspective of clusters}

The EU considers IoT a very powerful enabler of business and societal solutions and, as highlighted by the Commission Staff Working Document "Advancing the Internet of Things in Europe," 35 it will be the next Internet-enabled economic and societal innovation, with the potential to advance:

\footnotetext{
${ }^{35} \operatorname{SWD}(2016) 110$ final. Brussels, 19.4.2016.
} 
1. Industrial innovation, in that they play a key role in digitizing European Industry, using smart systems, cyber physical systems, and so on.

2. Management of complex systems in the widest sense: from smart cities and smart mobility to environmental systems, to operating any feedback-based system, also making use of artificial intelligence and Big Data.

3. Individual systems, such as smart living, wearables, and individual devices.

To better understand the role of IoT-relevant policies, clusters and their members were presented a number of discussion points on possible policy measures, their awareness as policy stakeholders and their assessment of the ongoing relevance of these measures to IoT at regional, national and EU levels. Table 12 presents the responses provided on the relevance of specific policy measures and regulations on the IoT ecosystems.

Significant percentages of respondents perceive that innovation support policies are actually not available, and in particular those focusing on EU IoT governance; on the Identification of emerging risks associated with IoT; on Standards mandates including IoT; and on IP law and data ownership.

Table 13 displays the opinions of cluster members on the availability of policy measures, that is them being in place and enforced.

The combined analysis of relevance - the need of the IoT for such policy types - and availability of policy measures allows to draw conclusions on the need for policy-makers to take action in specific fields. Five measures concerning IoT require regulation, namely EU-level governance of IoT; action for standardisation; IoT-specific risk assessment; IPR regulations and management; and support to labs and testing facilities (Table 14).

Ketels (2013) acknowledges the general consensus on the contribution of clusters to the economy, but also that the conceptual discussion has not always kept pace with the progress of policies. The author relates it to missing shared views on what cluster policy actually is. While there is a considerable amount of data on clusters, the same is not true for cluster policy evaluation. For the moment, impact assessments are "case-by-case analyses and tend to be focused on improving the specific policy program in place, not on broadly learning about better cluster policy" and a lot more has to be done to progress the cluster policy debate.

In conclusion, case studies confirm that there is no high demand by IoT clusters for concrete policy actions, such as support to innovation and pilot projects and the funding of IoT research and development. The reason for this was not indicated, but may be related to the awareness of business and innovation players of their own capabilities to address and solve operational and technical problems. Actually, the expectations of clusters seems focused on the overall regulatory and public communication framework and not for specific technological and business measures.

\section{Discussion}

\subsection{Overview of research results}

This policy study researches how innovation clusters actually enable IoT businesses and their developers, and support the development of IoT and of new innovators, such as small and medium sized enterprises and start-ups. It also provides indications on how public industrial policy, innovation policy, and development policies can be shaped to contribute to this important technology and application area.

IoT is a fast developing application area, it is horizontal across a vast set of fields of human activity and has the potential to boost the functionalities of applications in practical all areas of human activity. In this very historical moment, IoT can take advantage of a number of technological accelerations, which enable the take-up of interconnected devices triggering automated actions.

Rapid growth of IoT application builds on a set of cornerstones: the development of the internet in terms of users, infrastructures and applications; the availability of computing power; miniaturization; performance of energy and storage systems; the performance of connectivity, in particular that of wireless 
Table 12. Relevance of policy measures-all respondents $(\mathrm{N}=403)$

\begin{tabular}{|c|c|c|c|c|c|c|}
\hline & $\begin{array}{l}\text { Not at } \\
\text { all } \\
\text { relevant }\end{array}$ & $\begin{array}{c}\text { Somewhat } \\
\text { not } \\
\text { relevant }\end{array}$ & $\begin{array}{c}\text { Somewhat } \\
\text { relevant }\end{array}$ & $\begin{array}{l}\text { Highly } \\
\text { relevant }\end{array}$ & $\begin{array}{c}\text { Not } \\
\text { relevant }\end{array}$ & Relevant \\
\hline & (A) & (B) & (C) & (D) & $(\mathrm{A}+\mathrm{B})$ & $(\mathrm{C}+\mathrm{D})$ \\
\hline $\begin{array}{l}\text { Funding of IoT-related } \\
\text { research and development }\end{array}$ & $5.7 \%$ & $14.9 \%$ & $47.6 \%$ & $31.8 \%$ & $20.6 \%$ & $79.4 \%$ \\
\hline $\begin{array}{l}\text { Innovation and pilot projects } \\
\text { with IoT applications }\end{array}$ & $2.8 \%$ & $18.8 \%$ & $46.6 \%$ & $31.8 \%$ & $21.6 \%$ & $78.4 \%$ \\
\hline $\begin{array}{l}\text { Development of IoT } \\
\text { platforms cutting across } \\
\text { sectors, industries and the } \\
\text { value chains, and } \\
\text { investment in physical } \\
\text { platforms }\end{array}$ & $7.9 \%$ & $19.9 \%$ & $38.1 \%$ & $34.0 \%$ & $27.8 \%$ & $72.1 \%$ \\
\hline $\begin{array}{l}\text { Continuous monitoring of the } \\
\text { privacy and protection of } \\
\text { personal data questions }\end{array}$ & $6.8 \%$ & $21.2 \%$ & $35.9 \%$ & $36.1 \%$ & $28.0 \%$ & $72.0 \%$ \\
\hline $\begin{array}{l}\text { Standards mandates } \\
\text { including IoT }\end{array}$ & $5.6 \%$ & $24.7 \%$ & $32.2 \%$ & $37.5 \%$ & $30.3 \%$ & $69.7 \%$ \\
\hline $\begin{array}{l}\text { Public-private partnership } \\
\text { building on IoT } \\
\text { applications and other } \\
\text { incentives of aggregation }\end{array}$ & $6.5 \%$ & $25.6 \%$ & $32.6 \%$ & $35.2 \%$ & $32.1 \%$ & $67.8 \%$ \\
\hline $\begin{array}{l}\text { Identification of emerging } \\
\text { risks associated with IoT }\end{array}$ & $8.9 \%$ & $23.4 \%$ & $30.8 \%$ & $36.8 \%$ & $32.3 \%$ & $67.6 \%$ \\
\hline EU governance of IoT & $7.2 \%$ & $26.0 \%$ & $25.4 \%$ & $41.3 \%$ & $33.2 \%$ & $66.7 \%$ \\
\hline $\begin{array}{l}\text { Creation of/support for labs, } \\
\text { testing or technological } \\
\text { facilities }\end{array}$ & $9.2 \%$ & $24.2 \%$ & $31.8 \%$ & $34.9 \%$ & $33.4 \%$ & $66.7 \%$ \\
\hline $\begin{array}{l}\text { International dialogue (i.e., } \\
\text { joint actions, sharing of } \\
\text { best practices) }\end{array}$ & $9.8 \%$ & $24.3 \%$ & $30.7 \%$ & $35.1 \%$ & $34.1 \%$ & $65.8 \%$ \\
\hline Technology transfer services & $9.5 \%$ & $26.2 \%$ & $27.8 \%$ & $36.5 \%$ & $35.7 \%$ & $64.3 \%$ \\
\hline $\begin{array}{l}\text { Counselling on IP law and } \\
\text { data ownership }\end{array}$ & $11.0 \%$ & $26.0 \%$ & $25.7 \%$ & $37.3 \%$ & $37.0 \%$ & $63.0 \%$ \\
\hline
\end{tabular}

Abbreviations: IoT, Internet of Things; IP, intellectual property.

Source: IoT Innovation Cluster Study, ${ }^{36}$ direct IoT survey.

$5 \mathrm{G}$ and the availability of fast optical fibre connections; the power of artificial intelligence and machine learning, which is an enabler of decision support systems and smart automated actions.

There are innovation clusters with recognized functions and performance and they are subject to business cycles just like any other business venture. These cycles are amplified by the interactions of firms and actors in their cluster setting.

In a globalized connected society with activities, and, most of all value chains which disregard borders, scholars confirm that it is not Apple, Google, or Hewlett Packard, but Silicon Valley as a

${ }^{36}$ https://ec.europa.eu/digital-single-market/en/internet-of-things/clusters 
Table 13. Availability of policy measures-all respondents $(\mathrm{N}=424)$

\begin{tabular}{llc}
\hline & Available & Not available \\
\hline Innovation and pilot projects with IoT applications & $33.7 \%$ & $66.3 \%$ \\
Funding of IoT-related research and development & $31.3 \%$ & $68.9 \%$ \\
International dialogue (i.e.: joint actions, sharing of best practices) & $24.5 \%$ & $75.5 \%$ \\
Development of IoT platforms cutting across sectors, industries and the & $23.6 \%$ & $76.4 \%$ \\
$\quad$ value chains, and investment in physical platforms & & \\
Public-private partnership building on IoT applications and other & $22.9 \%$ & $77.1 \%$ \\
$\quad$ incentives of aggregation & & \\
Technology transfer services & $21.0 \%$ & $79.0 \%$ \\
Continuous monitoring of the privacy and protection of personal data & $20.5 \%$ & $79.0 \%$ \\
$\quad$ questions & $19.6 \%$ & $79.5 \%$ \\
Creation of/support for labs, testing or technological facilities & $15.1 \%$ & $80.4 \%$ \\
Counselling on IP law and data ownership & $14.4 \%$ & $85.6 \%$ \\
Standards mandates including IoT & $14.2 \%$ & $85.8 \%$ \\
Identification of emerging risks associated with IoT & $13.9 \%$ & $86.1 \%$ \\
\hline EU governance of IoT & & \\
\hline
\end{tabular}

Abbreviations: IoT, Internet of Things.

Source: IoT Innovation Cluster Study, ${ }^{37}$ direct IoT survey.

Table 14. IoT policy measures, their availability, relevance ranking, and action priority

\begin{tabular}{llcl}
\hline IoT policy measure & Availability & $\begin{array}{c}\text { Relevance } \\
\text { ranking }\end{array}$ & $\begin{array}{l}\text { Needed policy } \\
\text { action }\end{array}$ \\
\hline $\begin{array}{l}\text { EU-level governance } \\
\text { Standardization and mandates }\end{array}$ & Very low & 1 & Very high \\
Privacy and data protection monitoring & Very low & 2 & Very high \\
Support to innovation and pilot projects & Low & 3 & High \\
Support to PPPs & Medium & 4 & Low \\
IoT-specific risk assessment & Low & 5 & High \\
Technology transfer services & Very low & 6 & Very high \\
Intellectual property rights regulations and & Low & 7 & High \\
$\quad$ management & Very low & 8 & Very high \\
Development of cross sector, cross-industry & Low & 9 & High \\
$\quad$ platforms & Medium & 10 & Low \\
Funding of IoT R\&D & Very low & 11 & Very high \\
Support to labs and testing facilities & Low & 12 & High \\
Support to the international dialogue & & & \\
\hline
\end{tabular}

Abbreviation: IoT, Internet of Things.

Source: IoT Innovation Cluster Study. ${ }^{38}$

whole that competes with other innovation ecosystems in the global arena. It is not Baidu or Xiaomi who invade the global market, but the Chinese system of innovation, with its epicenter in Beijing or Shenzhen. It is not BMW, Daimler, Mercedes, or Robert Bosch who try to lead the automotive sector,

\footnotetext{
${ }^{37}$ ibidem.

38 ibidem.
} 
but the innovative clusters of Bavaria and Baden-Württemberg in South Germany (Ferras-Hernandez and Nylund, 2019).

Clusters have ever since been places where businesses and other actors have gathered to cooperate and to compete, sustained by the combined and multiplying action of several strengths, which mutually reinforce each other. In a global economy, the creation, operation, rise and fall of ecosystems and their innovative activities is accelerated by the combined and self-reinforcing action of five strengths: attraction, anticipation, rivalry, information, and interaction (Ferras-Hernandez and Nylund, 2019).

As a matter of fact, out of nearly 1,200 participants in the study's open survey, over 500 confirmed that they belonged to, or cooperated with, a cluster.

Businesses tend to agglomerate, researchers, innovators, and developers tend to agglomerate and cooperate in a dynamic and changeable process. Clusters are initiated mostly "bottom up" for the most diverse reasons, response to industrial and sectoral crises for example, and by the most diverse players, but also "top down" due to individual initiatives and policy programs.

There are cases where LMCs or large universities or research institutions successfully lead clusters, other cases, in which they are less successful. SMEs and start-ups are considered key players, because of their flexibility, adaptability, and innovative power, and, even if the innovative capacity of SMEs is strong, not all SMEs are equally able to generate innovation and value-added. They can take advantage of clusters only if these adopt rules and measures that are compatible with their specific structural and operational characteristics of dynamism, activeness and fragility. Start-ups have an even more particular standing, since they are considered a key driver of the development of technologies - and of IoT-advancing breakthrough innovation and application development and accelerating value chain dynamics in cluster ecosystems. They rely on the exchange of tacit and experiential knowledge exchange, benefitting from observation, exchange and practice: learning by doing, by using and by interacting (DUI), which leads to incremental innovation. It must be said that firm drivers of innovation are extremely heterogeneous, but that for SMEs the qualified STI interaction is essential (Parrilli and Elola, 2012).

IoT innovation clusters are fundamentally market and enterprise-driven and their sustainability is based on the value creation for their members on a continuous basis. A particular challenge for clusters is the rigidity of large enterprises, which may be incompatible with the flexibility needed to cooperate with small and medium enterprises and start-ups.

Innovation clusters provide a vast range of technological, innovation, and business services, which are specific to each experience and generate diversified impacts.

The cluster-specific success factors are (a) financing and funding; (b) an appropriate strategic process, adjusting the service offering to the requirements of the environment and of the stakeholders, structured cluster processes; and (c) structured focus on technology and applications and their development and the relevant technology development good practices.

\subsection{The impacts of clusters on enterprise and innovation performance and the role of public policies}

There is a vast literature, which assigns great value to innovation clusters and the agglomeration economy at large. Michael Porter is the author of seminal research on clusters and agglomeration economy. In his 1998 article (Porter, 1998b), He emphasizes the impacts of clusters on productivity and innovation performance of enterprises, which unfolds in three broad ways: increasing the productivity of their members; by driving the direction and pace of innovation, a factor of productivity increase; and by stimulating the creation of new business, which favors the expansion of and strengthening of the cluster " $A$ vibrant cluster can help any company in any industry compete in the most sophisticated ways, using the most advanced, relevant skills and technologies." According to Porter, and as confirmed by Moretti (2012) a cluster provides its members the benefits of a greater scale without creating formal joint ventures with other members at the cost of flexibility. Cluster formation undergoes a self-reinforcing cycle: Iin respect to industrial policy, Porter supports that the 
main responsibility of governments and their industrial policy is to create an environment that supports rising productivity.

Turkina et al. (2019) recommend collaboration of firms with well-established and networked industry peers and collective actions, possibly through broad inter-firm projects and partnerships. Furthermore, strong connections between highly performing industry peers and advanced research institutions and universities helps innovation performance beyond cluster life cycles.

However, when it comes to a sound evaluation of the impacts of cluster operations and their innovative performance, the situation looks different.

Beaudry and Breschi (2003) have more closely focused on the innovativeness of firms in clusters, using an econometric model to test whether firms in clusters are more innovative. The two authors conclude that the impact of clustering is likely to differ from cluster to cluster, depending on industry, type of firms and professional market in the region and that "it is not the size of the cluster in terms of own sector employment, but the importance of innovations by peers within the cluster that matters." They confirm that being located in a region with a critical mass of innovative firms increases innovation dynamics, benefitting from the spill-overs from a large stock of knowledge. On the contrary, quite strong disadvantages are observed in the case of a strong presence of non-innovative companies.

Other evaluations of cluster program effects (Wise et al., 2017) indicate that only a limited number of studies directly address the impacts of specific cluster programs on firm-level productivity, with mixed and generally un-convincing results. That is mostly because of the unavailability of reliable and appropriate productivity data and on the various other factors that may be influencing it. The Organization for Economic Cooperation and Development (OECD) in its Innovation Strategy 2015 an Agenda for Policy Action confirms that "evaluation of cluster policies are rare and often not very robust" (OECD, 2015). Generally speaking, there is positive evidence of the capacity of the public sector to leverage private sector investment, but it is revealing that none of the examined evaluations focus on the long-term impacts on growth and employment.

As pointed out by Schmiedeberg (2010) "the choice of indicators is not trivial, since all of them are criticised for having their deficiencies."

Žižka et al. (2018) have studied the ability of businesses within clusters to transform resources into registered industrial property rights and furthermore, the effectiveness of these businesses to trade industrial property rights and generate profits. These researchers have measured innovation performance comparing two samples of two different sectors, that is textile and nanotechnology, and firms members and nonmembers of clusters. The study, which adopted a Data Development Approach, demonstrated that the existence of a cluster produces greater innovation effects in traditional sectors than in emerging sectors. In the established textile sector, the cluster was a key factor to strengthen innovative capability and competitiveness, not so in the nanotechnology industry, where the cluster did not show the same impact. As pointed out by the authors of the paper themselves (Žižka et al., 2018), however, while these results are significant for the evaluation of specific, localized interventions in countries or regions and with reference to specific sectors, it is difficult to generalize them.

The elusiveness of the cluster concept for policy purposes makes it "chaotic, vague, elusive, and even expressly generic and contains the seed of its own demise" (Iritié, 2018), pointing at the fact that the cluster effect on innovativeness - and the competitiveness, economic, and employment — depends on the type of clusters considered, the industry and on the way the research is conceived and setup.

Giles Duranton's research work provides an extensive review and critical quantitative analysis of cluster policies with regards to the effects they generate and he challenges the scientific foundations of general cluster prosperity. His conclusions are that most scientific analyses of clusters rarely focus on the economic logic behind cluster policies and that most statements appear tautological, refer to "prosperous clusters such as Silicon Valley" and rarely quantify costs and benefits. Clusters, according to Duranton, exist and actually are designed to address pervasive market failures. What is unclear, he states, is what cluster policies should do to address these failures and how they should do it. In addition, benefits from clustering on local earnings and local productivity are low and that the local composition of economic activity does not drive prosperity, since creating clusters is only an intermediate outcome only weakly 
related to the prosperity policy-makers are interested in, making clustering not a choice variable that policy-makers can easily manipulate.

Duranton points out that most cluster models are not fully specified. To address this issue he proposes cluster models where a number of elements are specified, including (a) the spatial structure, including geographical variables (land, housing, infrastructure, and internal transport) and (b) production structure, possibly defining an aggregate production function, which directly relates primary factors to the output. In general, economies of scale are beneficial from a micro-economic and macro-economic point of view, but it must be considered that the sources of local increasing returns are also the source of inefficiencies and that more generally private and marginal returns will not in general coincide in a cluster. Cluster-related mechanisms can generate increasing returns but identifying the precise causal relationships will be difficult. Furthermore, economic agents do not receive compensation for the positive effects they generate, but they also do not have to compensate others for the positive effects they enjoy, implying a transfer of benefits. "Knowledge diffusion social returns are likely to exceed private returns because of the lack of reward associated with knowledge diffusion. It can be assumed that social marginal returns in clusters exceed private marginal returns (which means that successful individual businesses have a rather low incentive in taking part in clusters)" (Duranton, 2011).

Rampersad (2015) stipulates that the main reason for failure rates of innovation clusters is the lack of development of cluster relationships between members as well as the ineffective performance monitoring of outcomes of value toward stakeholders. Huber questions the benefit for firms members of clusters to access knowledge networks and technological knowledge spill overs, basing on the affirmation that there is simply no need to interact with other local companies or research institutions and that alternative sources of knowledge such as internal resources or the Internet are sufficient, or preferable, to be successful (Huber, 2012).

Clusters may inhibit innovations in that they might bring about negative externalities (congestion, raises in estate prices, inflation, and gentrification; Fang, 2015). Fang also acknowledges that clusters, on average, have positive effects on innovation and that there is a huge heterogeneity across studies and cases of clusters and that some variations in clusters' effect on innovation remain unexplained.

\section{Conclusions}

While it can be certainly affirmed, and grounded in literature, that there are certainly successful clusters, also besides from the much-cited Silicon Valley, such as the High Tech Campus Eindhoven, the Digital Media City of Seoul, the Cambridge Cluster, Tech City London. It must be recognized that the cluster landscape is as differentiated as the world of enterprises and that therefore the cluster experience and practice appear extremely difficult to transfer.

The IoT and its complex and sophisticated setup certainly can drive the development of ICT (information and communication technologies) as a whole and therefore the development of some particularly dynamic and effective clusters.

The clusters participating in the research underlying this study acknowledge the importance of policymaking to address some of the critical success factors of IoT such as EU-level governance, standardization and mandates, IoT-specific risk assessment, support to labs and testing facilities.

Enterprises and innovation actors have the natural tendency to aggregate, possibly generating collective benefits of knowledge critical mass and productivity boost. This has the potential to lead to individual and aggregate competitive advantage through the productivity gains achieved through value chain integration and cooperative innovation. But while there is evidence that clusters may function, it is by no means guaranteed that clusters will be successful or sustainable over time.

There are no standardized patterns of cluster composition: members are enterprises of different sizes, even if it seems that SMEs are in a better position to take advantage of cluster membership Clusters are fundamentally market and enterprise-driven and their sustainability is based on the value creation for their members on a continuous basis. Considering the majority of cluster assessment studies, only a very limited number of them actually go beyond tautological statements referring to "prosperous clusters such 
as Silicon Valley" and rarely quantify costs and benefits. Even though policy-makers and researchers have been debating the replication of the Silicon Valley model since over a decade and even if a significant amount of data and research has been carried out, the real set of driving factors and their combination has proven quite elusive (Morse, 2013).

The impact of clustering is likely to differ from cluster to cluster, depending on industry, type of firms and professional market in the region and positive impacts related to business agglomeration can only be generated by innovative firms. Very few studies directly address the impacts of specific cluster programs on firm-level productivity, with mixed and generally un-convincing results: studies show that benefits from clustering on local earnings and local productivity are low and that the local composition of economic activity does not drive prosperity, since creating clusters is only an intermediate outcome only weakly related to the prosperity policy-makers are interested in.

Policy implications are unclear and even more uncertain is the role and impact of cluster-oriented public policies: clustering is not a choice variable that policy-makers can easily manipulate. The authors consider the cluster approach more of a lens to examine and understand regional economies than a socioeconomic development policy instrument (Wolman and Hincapie, 2015).

In the end, clusters participating in the empirical research supporting this policy study clearly request, consistently with the conclusions of main studies, that policy-makers focus on framework conditions, both for clusters and for IoT, rather than taking an operational implementation role.

The list of IoT Innovation clusters resulting from the desk research

\begin{tabular}{lcccc}
\hline Cluster Name & SME & Large & Association & RTO \\
\hline Cap Digital & 765 & 75 & 6 & 364 \\
LSEC-Leaders in Security & 750 & 250 & & 63 \\
Aerospace Valley & 510 & 25 & & 10 \\
Digital Catapult & 390 & 103 & 53 \\
Minalogic & 305 & 42 & & 13 \\
MEDICEN PARIS REGION & 297 & 27 & & 27 \\
Systematic Paris-Region & 290 & 106 & 5 & 72 \\
Flanders' FOOD, FF & 210 & 100 & 1 & 37 \\
Photonics cluster OPTITEC & 148 & 5 & & 51 \\
Automotive Cluster @Business Upper Austria-OOO & 143 & 109 & & 17 \\
$\quad$ Wirtschaftsagentur & & & \\
OPTICS VALLEY & 134 & 17 & & 17 \\
FIIF & 133 & 43 & & 6 \\
Pôle MecaTech & 125 & 44 & & 95 \\
Images \& Réseaux & 104 & 31 & 7 & 12 \\
CenSec & 94 & 10 & 1 & 5 \\
Cluster Lumiere & 92 & 17 & & 17 \\
Swedish Smart Grid Cluster & 87 & 22 & & \\
DSP Valley & 86 & 3 & & 21 \\
S2E2 competitiveness cluster - Smart Electricity Cluster & 85 & 33 & & 43 \\
INFOPOLE Cluster TIC & 84 & 15 & 1 & 11 \\
Lifetech.brussels & 80 & 10 & & 4 \\
Human.technology Styria GmbH & 76 & 14 & & 15 \\
& & & &
\end{tabular}




\begin{tabular}{|c|c|c|c|c|}
\hline Cluster Name & SME & Large & Association & RTO \\
\hline Silicon Alps Cluster GmbH & 60 & 20 & 1 & 16 \\
\hline Estonian ICT Cluster & 57 & 13 & & \\
\hline AIOTI Alliance & 50 & 48 & 8 & 24 \\
\hline Arctic Design Cluster & 50 & 9 & & 64 \\
\hline Groen Licht Vlaandere & 50 & 10 & 1 & 7 \\
\hline Estonian Connected Health Cluster & 41 & 9 & & 6 \\
\hline Hungarian Mobility and Multimedia Cluster & 32 & 2 & & \\
\hline GERMAN INDUSTRY 4.0 & 30 & 14 & & 1 \\
\hline IoT Security Foundation & 30 & 12 & & 8 \\
\hline Cool Silicon e.V. & 26 & 6 & & \\
\hline Flanders Make & 25 & 57 & & 6 \\
\hline Smart Grid service cluster & 21 & 3 & & \\
\hline $\mathrm{IoF}$ & 21 & 24 & & 9 \\
\hline Smart Grid Service Cluster & 21 & 3 & & \\
\hline PrintoCent & 14 & 6 & & \\
\hline Danish Smart Cities & 11 & 7 & & 1 \\
\hline Silesian ICT \& Multimedia Cluster & 11 & & & \\
\hline Copenhagen Cleantech Cluster & 10 & 6 & & \\
\hline Hudiksvalls Hydraulikkluster & 10 & 2 & & \\
\hline MONICA & 10 & 4 & & 6 \\
\hline bIoTope & 8 & & 1 & 4 \\
\hline Electric mobility NO & 8 & 4 & & \\
\hline CREATE IoT & 8 & 3 & & 4 \\
\hline VICINITY & 7 & 3 & & 3 \\
\hline Synchronicity & 7 & 5 & & 7 \\
\hline Activage & 6 & 7 & & 11 \\
\hline inter-iot & 5 & 1 & 1 & 4 \\
\hline TagItSmart & 5 & 4 & & 3 \\
\hline AGILE & 4 & 4 & 1 & 3 \\
\hline symbIOTe & 4 & 2 & & 6 \\
\hline Unify IoT & 4 & 1 & & 2 \\
\hline IOTFORUM & 4 & 3 & 3 & 7 \\
\hline Cluster Microelectronics and Embedded Systems & 4 & 1 & & 4 \\
\hline Norwegian Smartgrid Centre (Borad) & 3 & 5 & & \\
\hline BIG Iot & 2 & 5 & & 4 \\
\hline BE-IOT & 1 & & 1 & 1 \\
\hline $\mathrm{CCC}$ & 1 & & & \\
\hline ERTICO-ITS & 1 & 2 & & 7 \\
\hline Produktion 2030 & 1 & 7 & & 3 \\
\hline Smartgridgotland & 1 & 2 & & \\
\hline Autopilot & 1 & 9 & & 10 \\
\hline ICT Cluster & 1 & & 3 & 4 \\
\hline Super IoT & 1 & 1 & & 6 \\
\hline Know-Center $\mathrm{GmbH}$ & 1 & 9 & 3 & 12 \\
\hline Protik Innovation Center & 1 & 3 & 1 & \\
\hline IoT Smart Santander Living Lab & 1 & & & \\
\hline $\mathrm{C} 2 \mathrm{C}-\mathrm{CC}$ & & 1 & & 11 \\
\hline
\end{tabular}




\begin{tabular}{|c|c|c|c|c|}
\hline Cluster Name & SME & Large & Association & RTO \\
\hline UNIFY-IOT & & & 1 & 3 \\
\hline BrainsBusiness ICT North Denmark & & 3 & & 3 \\
\hline DIH IoT & & & & 1 \\
\hline Finnish Industrial Internet Forum & & 3 & & 5 \\
\hline Innovation Network RoboCluster & & & 1 & 4 \\
\hline Innovation Network for Smart Energy (Inno-SE) & & & & 4 \\
\hline One Sea - Autonomous Maritime Ecosystem & & 5 & 1 & \\
\hline 5G Test Network Finland (5GTNF) & & & & \\
\hline Copenhagen Fintech & & & & 4 \\
\hline $\begin{array}{l}\text { Danish Technological Institute, Robot Technology, DTI } \\
\text { Robotics }\end{array}$ & & & & \\
\hline MADE - Manufacturing Academy of Denmark & & 5 & 1 & 18 \\
\hline Accelerating Photonics innovation for SME's (ACTPHAST 4.0) & & & & 17 \\
\hline Centre de recherche en aéronautique ASBL, Cenaero & & 1 & 3 & 1 \\
\hline Helsinki Living Lab - Forum Virium Helsinki & & 3 & & 1 \\
\hline Future Classroom Lab & & 6 & & \\
\hline Virtual Services and Open Innovation & & & & 6 \\
\hline WIRELESSINFO - Czech Living Labs & & & & 1 \\
\hline Smart City Lab (SCL) & & 1 & & 1 \\
\hline
\end{tabular}

Acknowledgments. The Author wishes to thank Francesco Mureddu for his valuable support and advice, while he retains all responsibilities for the statements made. This research draws on the results of the Study on mapping Internet of Things innovation clusters in Europe, Contract number 30-CE-0786039/00-02, carried out on behalf of Directorate General CNECT of the European Commission, Unit SMART 2015/0012 DG Communications Networks, Content \& Technology. The study was coordinated by the Joint Institute for Innovation Policy and involved its partners Joanneum Research, Tecnalia, VTT, and KPMG as a subcontractor. The views expressed in this paper are nevertheless exclusively those of the author and do not reflect the position neither of JIIP and its members nor of the European Commission.

Data Availability Statement. Unfortunately, at this point in time, it is not possible to make available clean raw data, due to inaccessibility of the original sources. The data in the tables is what is available at the moment of the paper release.

Author Contributions. Conceptualization: L.A.R.; Funding acquisition: L.A.R.; Investigation: L.A.R.; Methodology: L.A.R.; Writing - original draft: L.A.R.

Funding Statement. This research was not funded. It draws in part on the results of the Study on mapping Internet of Things innovation clusters in Europe, Contract number 30-CE-0786039/00-02, carried out on behalf of Directorate General CNECT of the European Commission, Unit SMART 2015/0012 DG Communications Networks, Content \& Technology. The study was coordinated by the Joint Institute for Innovation Policy and involved its partners Joanneum Research, Tecnalia, VTT, and KPMG as a subcontractor. The funder had no role in the decision to publish, or preparation of the manuscript. The views expressed in this paper are nevertheless exclusively those of the author and do not reflect the position neither of JIIP and its members nor of the European Commission.

Competing Interests. The author declares no competing interests exist.

\section{References}

Akpakwu GA, Silva BJ, Hancke GP and Abu-Mahfouz AM (2017) A survey on 5G networks for the internet of things: Communication technologies and challenges. IEEE Access 6, 3619-3647.

Andrienko R, 2021. The Role of Innovation Clusters in the Development of Innovative Environment. In VIII International Scientific and Practical Conference'Current Problems of Social and Labour Relations'(ISPC-CPSLR 2020). Atlantis Press, pp. 57-62.

Audretsch DB, Lehmann EE, Menter M and Seitz N (2019) Public cluster policy and firm performance: Evaluating spillover effects across industries. Entrepreneurship \& Regional Development 31, 150-165. 
Beaudry C and Breschi S (2003) Are firms in clusters really more innovative? Economics of Innovation and New Technology 12 , $325-342$.

Calvino F, Criscuolo C and Menon C (2016) No country for young firms?: Start-up dynamics and national policies. https://doi.org/ $10.1787 / 5 \mathrm{jm} 22 \mathrm{p} 40 \mathrm{c} 8 \mathrm{mw}-\mathrm{en}$

Capello R (1999) Spatial transfer of knowledge in high technology milieux: Learning versus collective learning processes. Regional Studies 33, 353-365.

Commission Staff Working Document (2020) A European strategy for data.

Commission Staff Working Document (2016a) Advancing the Internet of Things in Europe.

Commission Staff Working Document (2016b) Digitising European industry reaping the full benefits of a digital single market. Duranton G (2011) California Dreamin': The feeble case for cluster policies. Review of Economic Analysis 3, 3-45.

Ebersold K and Glass R (2015) The impact of disruptive technology: The internet of things. Issues in Information Systems 16, IV, 194-201.

Ellison G and Glaeser EL (1999) The geographic concentration of industry: Does natural advantage explain agglomeration? American Economic Review 89, 311-316.

Ellison G and Glaeser EL (1997) Geographic concentration in US manufacturing industries: A dartboard approach. Journal of Political Economy 105, 889-927.

Fang L (2015) Do clusters encourage innovation? A meta-analysis. Journal of Planning Literature 30, $239-260$.

Ferras-Hernandez X and Nylund PA (2019) Clusters as innovation engines: The accelerating strengths of proximity. European Management Review 16, 37-53.

He H, Maple C, Watson T, Tiwari A, Mehnen J, Jin Y and Gabrys B (2016) The security challenges in the IoT enabled cyberphysical systems and opportunities for evolutionary computing \& other computational intelligence.

Huber F (2012) Do clusters really matter for innovation practices in information technology? Questioning the significance of technological knowledge spillovers. Journal of Economic Geography 12, 107-126.

Huggins R and Thompson P (2017) Handbook of Regions and Competitiveness: Contemporary Theories and Perspectives on Economic Development. Cheltenham: Edward Elgar Publishing.

Ibrahim S and Fallah MH (2005) Drivers of innovation and influence of technological clusters. Engineering Management Journal $17,33-41$.

Iritié BJJ (2018) Economic issues of innovation clusters-based industrial policy: A critical overview. Global Business and Economics Review 20, 286-307.

Kaska K, Beckvard H and Minarik T (2019) Huawei, 5G and China as a security threat. NATO Cooperative Cyber Defence Center for Excellence (CCDCOE) 28.

Ketels C (2013) Cluster Policy: A Guide to the State of the Debate, in: Knowledge and the Economy. Berlin: Springer, pp. $249-269$.

Krugman P and Venables AJ (1996) Integration, specialization, and adjustment. European Economic Review 40, 959-967.

Lazzeretti L, Capone F, Caloffi A and Sedita SR (2019) Rethinking clusters. Towards a new research agenda for cluster research. European Planning Studies 27, 1879-1903.

Li S, Da Xu L and Zhao S (2018) 5G internet of things: A survey. Journal of Industrial Information Integration 10, 1-9.

Mahmoud R, Yousuf T, Aloul F and Zualkernan I (2015). Internet of things (IoT) security: Current status, challenges and prospective measures. In 2015 10th International Conference for Internet Technology and Secured Transactions (ICITST). IEEE, pp. 336-341.

Makedos I (2014) The collaboration of SMEs through clusters as defense against economic crisis [WWW Document]. Economics Research International. https://doi.org/10.1155/2014/407375

Manyika J, Chui M, Bisson P, Woetzel J, Dobbs R, Bughin J and Aharon D (2015) Unlocking the Potential of the Internet of Things. McKinsey Global Institute.

Martin P and Mayneris F (2011) Public support to clusters: A firm level study of french local productive systems. Regional Science and Urban Economics 41, 108-123.

Melachroinos KA and Spence N (2001) Manufacturing productivity growth across European Union states: 1978-94. Environment and Planning $A$ 33, 1681-1703.

Moretti E (2012) The New Geography of Jobs, Reprint edizione. ed. Boston: Mariner Books.

Morse S (2013) A model for developing urban innovation clusters. World Technopolis Review 2, 81-95.

OECD (2015) OECD Innovation Strategy 2015: An Agenda for Policy Action. Paris: OECD Publishing.

Palattella MR, Dohler M, Grieco A, Rizzo G, Torsner J, Engel T and Ladid L (2016) Internet of things in the 5G era: Enablers, architecture, and business models. IEEE Journal on Selected Areas in Communications 34, 510-527.

Pang Z (2013) Technologies and Architectures of the Internet-of-Things (IoT) for Health and Well-being (PhD Thesis). KTH Royal Institute of Technology.

Parrilli MD and Elola A (2012) The strength of science and technology drivers for SME innovation. Small Business Economics 39, 897-907.

Porter ME (2000) Location, competition, and economic development: Local clusters in a global economy. Economic Development Quarterly 14, 15-34.

Porter ME (1998a) Competitive Advantage of Nations. New York: Free Press.

Porter ME (1998b) Clusters and the New Economics of Competition. Boston: Harvard Business Review.

Rampersad GC (2015) Managing innovation clusters: A network approach. Journal of Management and Strategy 6, 9. 
Russell MG and Smorodinskaya NV (2018) Leveraging complexity for ecosystemic innovation. Technological Forecasting and Social Change 136, 114-131.

Schmiedeberg C (2010) Evaluation of cluster policy: A methodological overview. Evaluation 16, 389-412.

Speldekamp D, Knoben J, Saka-Helmhout A (2020) Clusters and firm-level innovation: A configurational analysis of agglomeration, network and institutional advantages in European aerospace. Research Policy 49, 103921.

Storper M and Venables AJ (2004) Buzz: Face-to-face contact and the urban economy. Journal of Economic Geography 4, 351-370.

Turkina E, Oreshkin B and Kali R (2019) Regional innovation clusters and firm innovation performance: An interactionist approach. Regional Studies 53, 1193-1206.

Wise E, Wilson J and Smith M (2017) Do clusters yield positive effects on firm performance? - A review of cluster programme effect analyses in Sweden and internationally.

Wolman H and Hincapie D (2015) Clusters and cluster-based development policy. Economic Development Quarterly 29, $135-149$.

Xie X, Wu Y and Ma G (2016) Driving forces of industrial clusters towards innovative clusters: Accelerating the innovation process. Asian Journal of Technology Innovation 24, 161-178.

Žižka M, Valentová V, Pelloneová N and Štichhauerová E (2018) The effect of clusters on the innovation performance of enterprises: Traditional vs new industries.

Cite this article: Remotti L. A (2021). IoT innovation clusters in Europe and the case for public policy. Data \& Policy, 3: e25. doi:10.1017/dap.2021.16 